\title{
PERANCANGAN SISTEM PENUNJANG KEPUTUSAN PEMILIHAN ANAK ASUH MENGGUNAKAN METODE TECHNIQUE FOR OTHERS REFERENCE BY SIMILARITY TO IDEAL SOLUTION (TOPSIS) PADA LAZ SEJAHTERA UMMAT
}

\author{
BOBI AGUSTIAN, OKE WIBOWO \\ Staf Pengajar Fakultas Teknik Prodi Teknik Informatika \\ Universitas Pamulang, Tangerang Selatan, Banten \\ E-mail : bobi_agustian@yahoo.com
}

\begin{abstract}
ABSTRAK
Pada proses penyaluran beasiswa anak asuh di LAZ Sejahtera Ummat sering terjadi ketidak sesuaian dengan kriterianya. Kriterianya meliputi penghasilan orang tua, jumlah tanggungan orang tua, rata-rata nilai, prestasi non akademik dan status anak. Maka dari itu dibutuhkan sebuah sistem penunjang keputusan untuk menyelesaikan permasalahan pemilihan anak asuh dengan metode Technique For Order Preference by Similarity to Ideal Solution (TOPSIS). TOPSIS merupakan suatu bentuk metode pendukung keputusan yang didasarkan pada konsep bahwa alternatif yang terbaik tidak hanya memiliki jarak terpendek dari solusi ideal positif tetapi juga memiliki jarak terpanjang dari solusi ideal negatif. Konsep ini banyak digunakan untuk menyelesaikan masalah keputusan secara praktis. Konsepnya sederhana dan mudah dipahami, komputasinya efisien dan memiliki kemampuan untuk mengukur kinerja relatif dari alternatifalternatif keputusan dalam bentuk matematis yang sederhana. Sistem yang dibuat menggunakan bahasa pemrograman PHP dan basis data mysql.
\end{abstract}

Kata Kunci : Sistem penunjang keputusan, TOPSIS, PHP, mysq1

\section{PENDAHULUAN}

Perkembangan Lembaga Amil Zakat Sejahtera Ummat merupakan salah satu lembaga yang bergerak dibidang sosial yaitu penghimpun dan pengelolaan zakat. LAZ Sejahtera Ummat ini berdiri dibawah naungan Yayasan Tangerang Sejahtera. Sejak berdirinya lembaga ini, telah banyak program sosial yang telah dilaksanakan seperti santunan anak yatim/piatu, sunat massal, nikah massal, pengobatan gratis, rumah singgah bagi anak asuh, pemberian sepeda sekolah, pelatihan dan seminar bagi anak asuh, beasiswa sekolah bagi anak asuh yang disertai pembinaan dengan dua pertemuan dalam satu bulan, dan beberapa program lainnya.

LAZ Sejahtera Ummat ini berdiri diresmikan sejak tahun 2004 dan sudah banyak meluluskan anak-anak berprestasi dari tingkat SD, SMP, SMA hingga Perguruan Tinggi namun dalam kondisi keluarganya yatim, piatu, atau dhuafa. Adapun misi dari LAZ Sejahtera Ummat ini adalah Berperan aktif dalam penghimpunan zakat, infaq, shodaqoh dan wakaf umat serta menyalurkannya untuk kesejahteraan umat.

Permasalahan penyaluran beasiswa anak asuh di LAZ Sejahtera Ummat yaitu agar sesuai dengan kriterianya. Kriterianya meliputi penghasilan orang tua, jumlah tanggungan orang tua, rata-rata nilai, prestasi non akademik dan status anak. Dalam pelaksanaanya sering terjadi pemilihan anak asuh yang tidak sesuai dengan kriteria yang diharapkan.

Salah satu metode yang bisa digunakan untuk menangani proses pemilihan anak asuh ialah dengan metode TOPSIS. TOPSIS merupakan suatu bentuk metode pendukung keputusan yang didasarkan pada konsep bahwa alternatif yang terbaik tidak hanya memiliki jarak terpendek dari solusi ideal positif tetapi juga memiliki jarak terpanjang dari solusi ideal negatif. Konsep ini banyak digunakan untuk menyelesaikan masalah keputusan secara praktis. Konsepnya sederhana dan mudah dipahami, komputasinya efisien dan memiliki kemampuan untuk mengukur 
kinerja relatif dari alternatif-alternatif keputusan dalam bentuk matematis yang sederhana.

Kelebihan metode TOPSIS dibanding dengan perhitungan biasa adalah dalam metode TOPSIS setiap alternatif dinilai tidak hanya berdasarkan kelebihannya tetapi juga berdasarkan kekurangannya. Kelebihan metode TOPSIS yang lain adalah dengan metode TOPSIS solusi ideal untuk penyelesaian masalah dapat diketahui dan penentuan peringkat pada setiap alternatif berdasarkan pula pada solusi ideal tersebut. Sedangkan jika dengan pembobotan biasa, tidak dapat diketahui solusi ideal-ideal dari permasalahan tersebut. Pada tahap awal dilakukan normalisasi matriks keputusan. Matriks keputusan sendiri merupakan matriks yang isinya adalah nilai setiap kriteria pada setiap alternatif. Normalisasi matriks tersebut adalah usaha untuk menyatukan setiap elemen matriks sehingga elemen pada matriks memiliki skala nilai yang seragam.

Metode TOPSIS ini dipilih karena mampu memilih alternatif terbaik dari sejumlah alternatif dan memiliki banyak kelebihan salah satunya yaitu setiap alternatif dinilai tidak hanya berdasarkan kelebihannya tetapi juga berdasarkan kekurangannya. Dalam hal ini alternatif yang dimaksud adalah lokasi terbaik berdasarkan kriteria-kriteria yang ditentukan dengan langkah-langkah metode TOPSIS. Hasil dari proses pengimplementasian metode TOPSIS dapat mengurutkan alternatif dari nilai yang terbesar ke nilai yang terkecil.

Berdasarkan uraian di atas, maka penulis bermaksud melakukan penelitian dengan judul "Perancangan Sistem Penunjang Keputusan Pemilihan Anak Asuh Menggunakan Metode Technique For Others Reference by Similarity to Ideal Solution (TOPSIS) Pada LAZ Sejahtera Ummat)". Diharapkan mempunyai kemampuan analisa pemilihan anak asuh yang berprestasi secara cepat, tepat, dan akurat.

\section{METODE PENELITIAN}

Metode TOPSIS merupakan metode pendukung keputusan yang didasarkan pada konsep dimana alternatif terpilih yang terbaik tidak hanya memiliki jarak terpendek dari solusi ideal positif, namun juga memiliki jarak terpanjang dari solusi ideal negatif (Kusumadewi, 2006). Konsep ini banyak digunakan pada beberapa model MADM untuk menyelesaikan masalah keputusan secara praktis. Hal ini disebabkan konsepnya sederhana dan mudah dipahami, komputasinya efisien, dan memiliki kemampuan untuk mengukur kinerja relatif dari alternatif-alternatif keputusan dalam bentuk matematis yang sederhana. Secara umum, langkah-langkah TOPSIS yaitu:

a. Membuat matriks keputusan yang ternormalisasi.

b. Membuat matriks keputusan yang ternormalisasi terbobot.

c. Menentukan matriks solusi ideal positif dan matriks solusi ideal negatif.

d. Menentukan jarak antara nilai setiap alternatif dengan matriks solusi ideal positif dan matriks solusi ideal negatif.

e. Menentukan nilai preferensi untuk setiap alternatif.

TOPSIS membutuhkan rating kerja setiap alternatif $A_{i}$ pada setiap kriteria $C_{j}$ yang ternormalisasi

$$
\mathrm{r}_{\mathrm{ij}}=\frac{x_{i_{j}}}{\sqrt{\sum_{i=1}^{m} x_{i j}^{2}}}
$$

Dengan $\mathrm{i}=1,2, \ldots \mathrm{m}$; dan $\mathrm{j}=1,2, \ldots \mathrm{n}$; Dimana:

$\mathrm{r}_{\mathrm{ij}}=$ matriks ternormalisasi $[\mathrm{i}][\mathrm{j}]$

$\mathrm{x}_{\mathrm{ij}}=$ matriks keputusan [i][j]

Solusi ideal positif $\mathrm{A}^{+}$dan solusi ideal negatif $\mathrm{A}^{-}$dapat ditentukan berdasarkan rating bobot ternormalisasi $\left(\mathrm{y}_{\mathrm{ij}}\right)$ sebagai:

$$
\begin{aligned}
& y_{i j}=w_{i} . r_{i j} ; \\
& \text { Dengan } i=1,2, \ldots m ; \text { dan } j=1,2, \ldots n ; \\
& A^{+}=\left(y_{1}^{+}, y_{2}^{+}, \ldots, y_{n}^{+}\right) ; \\
& A^{-}=\left(y_{1}^{-}, y_{2}^{-}, \ldots, y_{n}^{-}\right) ; \\
& \text {Dimana: } \\
& y_{i j}=\text { matriks ternormalisasi terbobot }
\end{aligned}
$$$$
\text { [i][j] }
$$

$\mathrm{W}_{\mathrm{i}}=$ vektor bobot [i] dari proses AHP

$\mathrm{y}^{+}{ }_{\mathrm{j}}=\max \mathrm{y}_{\mathrm{ij}}$, jika $\mathrm{j}$ adalah atribut keuntungan dan $\min \mathrm{y}_{\mathrm{ij}}$, jika $\mathrm{j}$ adalah atribut biaya

$\mathrm{y}_{\mathrm{j}}=\min \mathrm{y}_{\mathrm{ij}}$, jika $\mathrm{j}$ adalah atribut biaya keuntungan dan $\max \mathrm{y}_{\mathrm{ij}}$, jika $\mathrm{j}$ adalah atribut biaya

$\mathrm{j}=1,2, \ldots, \mathrm{n}$ 
ISSN 2541-1004

Jarak antara alternatif $A_{i}$ dengan solusi ideal positif:

$$
\begin{aligned}
& \mathrm{D}_{\mathrm{i}}^{+}=\sqrt{\sum_{i=1}^{n}\left(y_{i}^{+}-y_{i j}\right)^{2}} \\
& \mathrm{i}=1,2, \ldots, \mathrm{m} \\
& \text { Dimana: } \\
& \mathrm{D}_{\mathrm{i}}^{+}=\text {jarak alternatif } \mathrm{A}_{\mathrm{i}} \text { dengan solusi }
\end{aligned}
$$
ideal positif

$\mathrm{y}_{\mathrm{i}}^{+}=$solusi ideal positif [i] [i][j]

$\mathrm{y}_{\mathrm{ij}}=$ matriks normalisasi terbobot

Jarak antara alternatif $A_{i}$ dengan solusi ideal negatif:

$$
\begin{aligned}
& \mathrm{D}_{\mathrm{i}}^{-}=\sqrt{\sum_{j=1}^{n}\left(y_{i j}-y_{i}^{-}\right)^{2}} \\
& \mathrm{i}=1,2, \ldots, \mathrm{m} \\
& \text { Dimana: } \\
& \mathrm{D}_{\mathrm{i}}^{-}=\text {jarak alternatif } \mathrm{A}_{\mathrm{i}} \text { dengan solusi }
\end{aligned}
$$
ideal negatif

$\mathrm{y}_{\mathrm{i}}^{-}=$solusi ideal negatif [i]

$\mathrm{y}_{\mathrm{ij}}=$ matriks normalisasi terbobot [i][j]

Nilai preferensi untuk setiap alternatif (Vi) diberikan sebagai :

$$
\begin{aligned}
& \mathrm{V}_{\mathrm{i}}=\frac{D_{i}^{-}}{D_{i}^{-}+D_{i}^{+}} \\
& \mathrm{i}=1,2, \ldots, \mathrm{m} \\
& \text { Dimana: } \\
& \mathrm{V}_{\mathrm{i}}=\text { kedekatan tiap alternatif }
\end{aligned}
$$
terhadap solusi ideal

$\mathrm{D}_{\mathrm{i}}^{+}=$jarak alternatif $\mathrm{A}_{\mathrm{i}}$ dengan solusi ideal positif

$D_{i}^{-}=$jarak alternatif $A_{i}$ dengan solusi ideal negatif

\section{PEMBAHASAN}

\section{a. Implementasi Metode TOPSIS}

Pada analisa metode ini menerangkan mengenai perhitungan penentuan beasiswa dengan menggunakan metode TOPSIS. Sebelum perhitungan dilakukan terlebih dahulu menentukan kriteria dalam penentuan beasiswa, adapun tabel kriteria yang digunakan yaitu:

Tabel 3.1 Kriteria yang Digunakan

\begin{tabular}{|c|c|c|c|}
\hline Kriteria & Keterangan & Satuan & Atribut \\
\hline $\mathrm{C} 1$ & $\begin{array}{c}\text { Penghasilan } \\
\text { Orang Tua }\end{array}$ & $\mathrm{Rp}$ & Cost \\
\hline
\end{tabular}

\begin{tabular}{|c|c|c|c|}
\hline C2 & $\begin{array}{c}\text { Jumlah } \\
\text { Tanggungan } \\
\text { Orang tua }\end{array}$ & Anak & Benefit \\
\hline C3 & $\begin{array}{c}\text { Rata-rata } \\
\text { nilai }\end{array}$ & Nilai & Benefit \\
\hline C4 & $\begin{array}{c}\text { Prestasi Non } \\
\text { Akademik }\end{array}$ & Nilai & Benefit \\
\hline C5 & Status Anak & Nilai & Benefit \\
\hline
\end{tabular}

Selanjutnya penilaian dengan memberikan pembobotan setiap kriteria yang ditunjukkan pada Tabel 3.2 yang jika dijumlah menjadi 100. Rating kecocokan untuk setiap alternatif pada setiap kriteria ditunjukkan pada Tabel 3.3 dan tingkat kepentingan untuk setiap kriteria pada Tabel 3.4 yaitu:

Tabel 3.2 Bobot yang Digunakan

\begin{tabular}{|c|c|}
\hline Kriteria & Bobot \\
\hline C1 & 15 \\
\hline C2 & 20 \\
\hline C3 & 25 \\
\hline C4 & 15 \\
\hline C5 & 25 \\
\hline
\end{tabular}

Tabel 3.3 Rating Kecocokan

\begin{tabular}{|c|c|}
\hline Nilai & Keterangan \\
\hline 1 & Sangat kurang \\
\hline 2 & Kurang \\
\hline 3 & Cukup \\
\hline 4 & Tinggi \\
\hline 5 & Sangat tinggi \\
\hline
\end{tabular}

Tabel 3.4 Tingkat kepentingan

\begin{tabular}{|c|c|}
\hline Nilai & Keterangan \\
\hline 1 & Sangat kurang \\
\hline 2 & Kurang \\
\hline 3 & Cukup \\
\hline 4 & Tinggi \\
\hline 5 & Sangat tinggi \\
\hline
\end{tabular}

Berikut merupakan tabel penilaian kriteria dari kriteria penghasilan orang tua (C1), jumlah tanggungan orang tua (C2), rata-rata nilai (C3), prestasi non akademik (C4), dan status anak (C5).

Tabel 3.5 Nilai Kriteria Penghasilan orang tua

\begin{tabular}{|c|c|c|}
\hline $\begin{array}{c}\text { Penghasilan } \\
\text { Orang Tua (C1) }\end{array}$ & Rating & Nilai \\
\hline
\end{tabular}




\begin{tabular}{|c|c|c|}
\hline $\begin{array}{c}\text { Rp. } 500.000-\text { Rp. } \\
1.000 .000\end{array}$ & $\begin{array}{c}\text { Sangat } \\
\text { sedikit }\end{array}$ & 1 \\
\hline $\begin{array}{c}\text { Rp. } 1.000 .001- \\
\text { Rp. } 2.000 .000\end{array}$ & Sedikit & 2 \\
\hline $\begin{array}{c}\text { Rp. } 2.000 .001- \\
\text { Rp. 3.000.000 }\end{array}$ & Sedang & 3 \\
\hline $\begin{array}{c}\text { Rp. 3.000.001- } \\
\text { Rp. } 4.000 .000\end{array}$ & Banyak & 4 \\
\hline$>$ Rp. 4.000 .000 & $\begin{array}{c}\text { Sangat } \\
\text { banyak }\end{array}$ & 5 \\
\hline
\end{tabular}

Tabel 3.6 Nilai Kriteria Jumlah Tanggungan Orang Tua

\begin{tabular}{|c|c|c|}
\hline $\begin{array}{c}\text { Jumlah } \\
\text { Tanggungan } \\
\text { (C2) }\end{array}$ & Rating & Nilai \\
\hline 1 Anak & $\begin{array}{c}\text { Sangat } \\
\text { sedikit }\end{array}$ & 1 \\
\hline 2 Anak & Sedikit & 2 \\
\hline 3 Anak & Sedang & 3 \\
\hline 4 Anak & Banyak & 4 \\
\hline$>4$ Anak & $\begin{array}{c}\text { Sangat } \\
\text { banyak }\end{array}$ & 5 \\
\hline
\end{tabular}

Tabel 3.7 Nilai Kriteria Rata-rata Nilai

\begin{tabular}{|c|c|c|}
\hline $\begin{array}{c}\text { Rata-rata } \\
\text { Nilai (C3) }\end{array}$ & Rating & Nilai \\
\hline$<50$ & $\begin{array}{c}\text { Sangat } \\
\text { Rendah }\end{array}$ & 1 \\
\hline $51-60$ & Rendah & 2 \\
\hline $61-70$ & Sedang & 3 \\
\hline $71-80$ & Tinggi & 4 \\
\hline$>80$ & $\begin{array}{c}\text { Sangat } \\
\text { tinggi }\end{array}$ & 5 \\
\hline
\end{tabular}

Tabel 3.8 Nilai Kriteria Prestasi Non Akademik

\begin{tabular}{|c|c|c|}
\hline $\begin{array}{c}\text { Prestasi } \\
\text { Non } \\
\text { Akademik } \\
(\mathrm{C} 4)\end{array}$ & Rating & Nilai \\
\hline $\begin{array}{c}\text { Tidak } \\
\text { Berprestasi }\end{array}$ & $\begin{array}{c}\text { Sangat } \\
\text { Rendah }\end{array}$ & 1 \\
\hline $\begin{array}{c}\text { Tingkat } \\
\text { kecamatan }\end{array}$ & Rendah & 2 \\
\hline $\begin{array}{c}\text { Tingkat } \\
\text { Kabupaten }\end{array}$ & Sedang & 3 \\
\hline
\end{tabular}

\begin{tabular}{|c|c|c|}
\hline $\begin{array}{c}\text { Tingkat } \\
\text { Provinsi }\end{array}$ & Tinggi & 4 \\
\hline $\begin{array}{c}\text { Tingkat } \\
\text { Nasional }\end{array}$ & $\begin{array}{c}\text { Sangat } \\
\text { tinggi }\end{array}$ & 5 \\
\hline
\end{tabular}

Tabel 3.9 Nilai Kriteria Status Anak

\begin{tabular}{|c|c|c|}
\hline $\begin{array}{c}\text { Status Anak } \\
(\text { C5 })\end{array}$ & Rating & Nilai \\
\hline $\begin{array}{c}\text { Masih } \\
\text { Lengkap }\end{array}$ & Lengkap & 1 \\
\hline Yatim/Piatu & Tidak Lengkap & 3 \\
\hline Yatim Piatu & $\begin{array}{c}\text { Sanget Tidak } \\
\text { Lengkap }\end{array}$ & 5 \\
\hline
\end{tabular}

Dalam menentukan beasiswa penulis mengambil 3 (tiga) calon anak asuh yang dijadikan contoh yaitu Alief (A1), Khaerul (A2), dan Niken (A3). Data-data dari setiap calon anak asuh dimasukkan kedalam Tabel 3.10 di bawah ini:

Tabel 3.10 Contoh Data Calon Anak Asuh

\begin{tabular}{|c|c|c|c|c|c|}
\hline A & $\mathrm{C} 1$ & $\mathrm{C} 2$ & $\begin{array}{l}\mathrm{C} \\
3\end{array}$ & $\mathrm{C} 4$ & $\mathrm{C} 5$ \\
\hline $\begin{array}{l}\text { (A1) } \\
\text { Alief }\end{array}$ & $\begin{array}{l}\text { Rp. } \\
2.250 .000\end{array}$ & $\begin{array}{l}2 \\
\text { Anak }\end{array}$ & 75 & $\begin{array}{l}\text { Tingkat } \\
\text { kecamatan }\end{array}$ & $\begin{array}{l}\text { Masih } \\
\text { lengkap }\end{array}$ \\
\hline $\begin{array}{l}\text { (A2) } \\
\text { Khaerul }\end{array}$ & $\begin{array}{l}\text { Rp. } \\
2.700 .000\end{array}$ & $\begin{array}{l}4 \\
\text { Anak }\end{array}$ & 81 & $\begin{array}{l}\text { Tidak } \\
\text { berprestasi }\end{array}$ & $\begin{array}{l}\text { Masih } \\
\text { lengkap }\end{array}$ \\
\hline $\begin{array}{l}\text { (A3) } \\
\text { Niken }\end{array}$ & $\begin{array}{l}\text { Rp. } \\
500.000\end{array}$ & $\begin{array}{l}3 \\
\text { Anak }\end{array}$ & 80 & $\begin{array}{l}\text { Tidak } \\
\text { berprestasi }\end{array}$ & Yatim \\
\hline
\end{tabular}

Keterangan:

$\mathrm{A}=$ Alternatif

$\mathrm{C} 1=$ Kriteria Penghasilan Orang Tua

$\mathrm{C} 2=$ Kriteria Jumlah Tanggungan Orang

Tua

C3 = Kriteria Rata-rata Nilai

C4 $=$ Kriteria Prestasi Non Akademik

C5 $=$ Kriteria Status Anak

Selanjutnya, Menentukan rating kecocokan setiap alternatif pada setiap kriteria. Adapun data rating kecocokan dari setiap alternatif dapat dilihat pada tabel 3.11 berikut ini:

Tabel 3.11 Rating Kecocokan dari Setiap Alternatif Pada Setiap Kriteria

\begin{tabular}{|c|c|c|c|c|c|}
\hline A & C1 & C2 & C3 & C4 & C5 \\
\hline A1 & 3 & 2 & 4 & 2 & 1 \\
\hline A2 & 3 & 4 & 5 & 1 & 1 \\
\hline
\end{tabular}




\begin{tabular}{|l|l|l|l|l|l|}
\hline A3 & 1 & 3 & 4 & 1 & 3 \\
\hline
\end{tabular}

Setelah kriteria-kriteria yang sudah ditulis diatas maka perhitungan dengan metode TOPSIS akan dilakukan. Adapun langkah-langkah perhitungan TOPSIS sebagai berikut:

a. Membuat matriks keputusan normalisasi

$$
\begin{aligned}
& |\mathrm{X} 1|=\sqrt{3^{2}+3^{2}+1^{2}}= \\
& \sqrt{9+9+1}=\sqrt{19}=4,35890 \\
& \mathrm{r}_{11}=\frac{X 11}{X 1}=\frac{3}{4,35890}=0,68825 \\
& \mathrm{r}_{21}=\frac{X 21}{X 1}=\frac{3}{4,35890}=0,68825 \\
& \mathrm{r}_{31}=\frac{X 31}{X 1}=\frac{1}{4,35890}=0,22942 \\
& |\mathrm{X} 2|=\sqrt{2^{2}+4^{2}+3^{2}}= \\
& \sqrt{4+16+9}=\sqrt{29}=5,38516 \\
& \mathrm{r}_{12}=\frac{X 12}{X 2}=\frac{2}{5,38516}=0,37139 \\
& \mathrm{r}_{22}=\frac{X 22}{X 2}=\frac{4}{5,38516}=0,74278 \\
& \mathrm{r}_{32}=\frac{X 32}{X 2}=\frac{3}{5,38516}=0,55709 \\
& |\mathrm{X} 3|=\sqrt{4^{2}+5^{2}+4^{2}}= \\
& \sqrt{16+25+16}=\sqrt{57}=7,54983 \\
& \mathrm{r}_{13}=\frac{X 13}{X 3}=\frac{4}{7,54983}=0,52981 \\
& \mathrm{r}_{23}=\frac{X 2}{X 3}=\frac{5}{7,54983}=0,66227 \\
& \mathrm{r}_{33}=\frac{X 33}{X 3}=\frac{4}{7,54983}=0,52981 \\
& |\mathrm{X} 4|=\sqrt{2^{2}+1^{2}+1^{2}}= \\
& \sqrt{4+1+1}=\sqrt{6}=2,44949 \\
& \mathrm{r}_{14}=\frac{X 14}{X 4}=\frac{2}{2,44949}=0,8165 \\
& \mathrm{r}_{24}=\frac{X 24}{X 4}=\frac{1}{2,44949}=0,40825 \\
& \mathrm{r}_{34}=\frac{X 34}{X 4}=\frac{1}{2,44949}=0,40825 \\
& |\mathrm{X} 5|=\sqrt{1^{2}+1^{2}+3^{2}}= \\
& \sqrt{1+1+9}=\sqrt{11}=3,31662 \\
& \mathrm{r}_{15}=\frac{X 15}{X 5}=\frac{1}{3,31662}=0,30151 \\
& \mathrm{r}_{25}=\frac{X 25}{X 5}=\frac{1}{3,31662}=0,30151 \\
& \mathrm{r}_{35}=\frac{X 35}{X 5}=\frac{3}{3,31662}=0,90453 \\
& \mathrm{r}_{\mathrm{ij}}
\end{aligned}
$$$$
\left\{\begin{array}{ccccc}
0,68825 & 0,37139 & 0,52981 & 0,8165 & 0,30151 \\
0,68825 & 0,74278 & 0,66227 & 0,40825 & 0,30151 \\
0,22942 & 0,55709 & 0,52981 & 0,40825 & 0,90453
\end{array}\right\}
$$

b. Membuat matriks keputusan yang ternormalisasi terbobot

$$
\mathrm{y}_{\mathrm{ij}}=\mathrm{w}_{\mathrm{i}} \cdot \mathrm{r}_{\mathrm{ij}}
$$

Diketahui:

(25)\}

$$
\mathrm{W}_{\mathrm{i}}=\{(15),(20),(25),(15),
$$

$$
\mathrm{r}_{\mathrm{ij}}
$$

$\left\{\begin{array}{ccccc}0,68825 & 0,37139 & 0,52981 & 0,8165 & 0,30151 \\ 0,68825 & 0,74278 & 0,66227 & 0,40825 & 0,30151 \\ 0,22942 & 0,55709 & 0,52981 & 0,40825 & 0,90453\end{array}\right\}$

$\left\{\begin{array}{cccccc}w_{1} \cdot r_{11} & w_{2} \cdot r_{12} & w_{3} \cdot r_{13} & w_{4} \cdot r_{14} & w_{5} \cdot r_{15} \\ w_{1} \cdot r_{21} & w_{2} \cdot r_{22} & w_{3} \cdot r_{23} & w_{4} \cdot r_{24} & w_{5} \cdot r_{25} \\ w_{1} \cdot r_{31} & w_{2} \cdot r_{32} & w_{3} \cdot r_{33} & w_{4} \cdot r_{34} & w_{5} \cdot r_{35}\end{array}\right\}$ Jawab:

$\mathrm{y}_{\mathrm{ij}}=$ $\left\{\begin{array}{lllll}10,32371 & 7,42781 & 13,24532 & 12,24745 & 7,53778 \\ 10,32371 & 14,85563 & 16,55665 & 6,12372 & 7,53778 \\ 3,44124 & 11,14172 & 13,24532 & 6,12372 & 22,61335\end{array}\right\}$

c. Menentukan matriks solusi ideal positif

$$
\operatorname{Min}\left\{\mathrm{y}_{1}^{+}=\right.
$$

$10,32371 ; 10,32371 ; 3,44124\}=$ 3,44124

$\mathrm{y}_{2}{ }^{+}=$
Max \{
$7,42781 ; 14,85563 ; 11,14172\}=$
14,85563

$\operatorname{Max}\{$

$13,24532 ; 16,55665 ; 13,24532\}=$

16,55665

$\operatorname{Max}\{$

$$
\mathrm{y}_{4}{ }^{+}=
$$

$12,24745 ; 6,12372 ; 6,12372\}=$ 12,24745

$\operatorname{Max}\{$

$$
\mathrm{y}_{5}{ }^{+}=
$$

$7,53778 ; 7,53778 ; 22,61335\}=$ 22,61335

$$
\mathrm{A}^{+}=\{
$$

3,44124; 14,85563; 16,55665; 12,24745; 22,61335 \}

d. Menentukan matriks solusi ideal negatif

$\operatorname{Max}\left\{\mathrm{y}^{-2}=\right.$ 
$10,32371 ; 10,32371 ; 3,4412\}=$

10,32371

$$
\mathrm{y}_{2}=
$$

$\operatorname{Min}\{$

$7,42781 ; 14,85563 ; 11,14172\}=$

7,42781

$\operatorname{Min}\{$

$$
\mathrm{y}^{-}=
$$

$13,24532 ; 16,55665 ; 13,24532\}=$

13,24532

$$
\mathrm{y} 4^{-}=
$$

\}$=6,12372$

$$
\mathrm{y} 5^{-}=
$$

$\operatorname{Min}\{7,53778 ; 7,53778 ; 22,61335$

\}$=7,53778$

$\mathrm{A}^{-}$

$=\{$

10,$32371 ; 7,42781 ; 13,24532 ; 6,12372 ; 7,53778$

\}

e. Jarak antar setiap alternatif dengan matriks solusi ideal positif
$\operatorname{Min}\{12,24745 ; 6,12372 ; 6,12372$

$$
\begin{aligned}
& \mathrm{D}_{\mathrm{i}}^{+}=\sqrt{\sum_{i=1}^{n}\left(y_{i}{ }^{+}-y_{i j}\right)^{2}} \\
& \mathrm{D}_{1}{ }^{+}=
\end{aligned}
$$

$$
\begin{aligned}
& \mathrm{D}_{\mathrm{i}}^{-}=\sqrt{\sum_{j=1}^{n}\left(y_{i j}-y_{i}^{-}\right)^{2}} \\
& \mathrm{D}^{-} \\
& = \\
& \sqrt{\begin{array}{r}
(10,32371-10,32371)^{2}+(7,42781-7,42781)^{2}+(13,24 \\
(12,24745-6,12372)^{2}+(7,53778-7,537
\end{array}} \\
& =\sqrt{0+0+0+37.50005+0} \\
& =\sqrt{37,50005}=6,12373 \\
& \mathrm{D}_{2}{ }^{-} \\
& = \\
& (10,32371-10,32371)^{2}+(14,85563-7,42781)^{2}+(16,55 \\
& (6,12372-6,12372)^{2}+(7,53778-7,5377 \\
& = \\
& \sqrt{0+55,17247+10,96494+0+0} \\
& \mathrm{D}_{3}^{-} \\
& =\sqrt{66,13741}=8,13249
\end{aligned}
$$

$=$

$(3,44124-10,32371)^{2}+(11,14172-7,42781)^{2}+(13,245$ $(6,12372-6,12372)^{2}+(22,61335-7,5377$ i

$\sqrt{47,36845+13,79313+0+0+227,27284}$ $=\sqrt{288,43442}=16,98336$

$(3,44124-10,32371)^{2}+(14,85563-7,42781)^{2}+(16,55665-13,24532)^{2}+$

$(12,24745-12,24745)^{2}+(22,6138$ - Mteneatukan nilai preferensi

untuk setiap alternatif

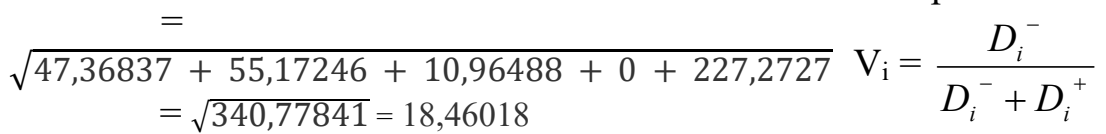

$\frac{\mathrm{D}_{2}{ }^{+}=}{(3,44124-10,32371)^{2}+(14,85563-14,85563)^{2}+(16,55665-16,56,66393)^{273}+18,46018}=$

$$
\sqrt{(3,44}
$$

$=$

$\frac{(12,24745-6,12372)^{2}+(0,1029-7,5377,8) 12373}{24,58391}=0,2491$

$\sqrt{47,36837+0+0+37,50002+227,2727}$

$=\sqrt{312,14109}=17,66752$

$\frac{\mathrm{D}_{3}{ }^{+}=}{8,13249}$

$\mathrm{V}_{2}=\frac{8,13249}{8,13249+17,66752}=$

$(12,24745-6,12372)^{2}+(22,61335-22,61335)^{2}$

$$
\mathrm{V}_{3}=\frac{16,98336}{16,98336+7,89038}=
$$

$=$

$$
\begin{gathered}
= \\
\sqrt{0+13,79313+10,96488+37,50002+0} \\
=\sqrt{62,25803}=7,89038
\end{gathered}
$$

f. Jarak antar setiap alternatif dengan matriks solusi ideal negatif $\frac{16,98336}{24,87374}=0,68278$

Kemudian melakukan pengurutan calon anak asuh 
berdasarkan Nilai $\mathrm{V}_{\mathrm{i}}$ yang didapat mulai dari yang terbesar sampai yang terkecil.

Alternatif pertama berada di $V_{3}=$ Niken Dewita Febrian (A3)

Alternatif kedua berada di $\mathrm{V}_{2}=$ Khaerul Fathurahman (A2) Alternatif ketiga berada di $\mathrm{V}_{1}=$ Alief Aziana Rizky (A1)

\section{KESIMPULAN}

Kesimpulan pada penelitian ini adalah bagaimana hasil perhitungan menggunakan metode TOPSIS dalam mengimplementasikan sistem pendukung keputusan pemilihan anak asuh

1. Metode TOPSIS dapat menghasilkan pilihan yang paling akurat dalam pemilihan anak asuh.

2. Hasil perhitungan menggunakan metode TOPSIS menghasilkan pemilihan yang akurat dengan hasil ahir pemilihan kepada kandidat yang memiliki rangking tertinggi yaitu 0,68278

\section{SARAN}

Dari hasil implementasi dan pengujian ini, penulis menyadari masih terdapat banyak kekurangan dan kesalahan dalam pengembangan sistem ini. Saransaran yang dapat penulis berikan antara lain:

1. Diharapkan ada peniliti lain yang mengembangkan sistem penunjang keputusan pemilihan anak asuh menggunakan metode yang lain.

2. Diharapkan sistem penunjang keputusan ini dapat melakukan penambahan kriteria seiring perkembangan kebutuhan pengguna sistem sehingga dapat meningkatkan kinerja sistem.

\section{DAFTAR PUSTAKA}

[1] Arbian, D. (2017). Sistem Pendukung Keputusan (SPK) Pemberian Beasiswa Berbasis TOPSIS (Studi Kasus Yayasan Pendidikan Al-Hikmah Bululawang Malang). Jurnal Ilmiah
Teknologi dan Informasi ASIA (JITIKA), 11(1).

[2] Arief, M. R. (2011). Pemograman Web Dinamis Menggunakan PHP dan MySQL. Yogyakarta: ANDI.

[3] Aswati, S., dkk. (2015). Sistem Pendukung Keputusan Penerima Beasiswa Pendidikan Yayasan (Studi Kasus Stmik Royal) Dengan Metode Simple Additive Weight. Seminar Nasional Sistem Informasi Indonesia.

[4] Athoillah, A., \& Marzuki. (2016). Sistem Informasi Penerimaan Siswa Baru Berbasis Web Pada SMK Informatika Yasma. Jurnal sistem informasi STMIK antar bangsa, 9(1).

[5] Frank, T. (2010). Model Driven Architecture with Enterprise Architect. California: Chepas Consulting.

[6] Gunanto. (2010). Pembuatan Sistem Informasi Perpustakaan Berbasis Web Dengan Php Dan Mysql. Universitas Surakarta.

[7] Irawan, A., Hasna, A., \& Pahlevi, R. (2016). Sistem Informasi Perdagangan Pada Pt Yoltan Sari Menggunakan Php Berbasis Web. Jurnal POSITIF, 1(2).

[8] Kadir, A. (2011). Buku Pintar jQuery dan PHP. Yogyakarta: ANDI.

[9] Kadir, A. (2014). Pengenalan Sistem Informasi Edisi Revisi. Yogyakarta: ANDI.

[10] Kirom, D. N., Bilfaqih, \& Effendie. (2012). Sistem Informasi Manajemen Beasiswa ITS Berbasis Sistem Pendukung Keputusan Menggunakan Analytical Hierarchy Process. JURNAL TEKNIK POMITS, 1(1).

[11] Kurniawan, D., \& Java Creativity. (2010). 145 Freeware Pilihan Untuk Berbagai Kebutuhan. Jakarta: Elex Media Komputindo.

[12] Kusrini. (2006). Konsep dan Aplikasi Sistem Pendukung Keputusan. Yogyakarta: ANDI.

[13] Kusumadewi, S., \& dkk. (2006). Fuzzy Multi Attribute Decision Making. Yogyakarta: Graha Ilmu.

[14] Lasminiasih, Shandi, Akbar, A., Andriansyah, M., \& Utomo, R. (2016). Perancangan Sistem Informasi Kredit Mikro Mahasiswa Berbasis Web. Jurnal Sistem Informasi (JSI), 8(1). 
[15] Nugroho, A. (2009). Rekayasa Perangkat Lunak Menggunakan UML dan Java. Yogyakarta: ANDI.

[16] Nugroho, A. (2010). Rekayasa Perangkat Lunak Berorientasi Objek dengan Metode USDP. Yogyakarta: ANDI.

[17] Nugroho, B. (2011). Trik dan Rahasia Membuat Aplikasi Web dengan PHP. Yogyakarta: GAVA MEDIA.

[18] Pamungkas, A. W., Nugroho, D., \& Siswanti, S. (2014). Sistem Pendukung Keputusan Penerimaan Beasiswa Kurang Mampu Smk Harapan Dengan Metode Simple Additive Weighting (SAW). Jurnal TIKomSiN, ISSN : 2338-4018.

[19] Rizky, S. (2011). Konsep Dasar Rekayasa Perangkat Lunak. Jakarta: PT. Prestasi Pustakaraya.

[20] Rosa, A. S., \& Shalahuddin, M. (2013). Rekayasa Perangkat Lunak. Bandung: Informatika.

[21] Sibero, A. (2013). Web Programming Power Pack. Yogyakarta: MediaKom.

[22] Sommerville, I. (2011). Software Engineering 9th Edition. AddisonWesley.

[23] Surya, C. (2014). Sistem Pendukung Keputusan Rekomendasi Penerima Beasiswa Menggunakan Fuzzy Multi Attribut Decision Making (FMADM) dan Simple Additive Weighting (SAW). Jurnal Rekayasa Elektrika, 11(4).

[24] Sutabri, T. (2012). Analisis Sistem Informasi. Yogyakarta: CV ANDI OFFSET.

[25] Tohari, H. (2014). astah. Madiun: ANDI.

[26] Turban, E. (2005). Sistem Pendukung Keputusan dan Sistem Cerdas. Yogyakarta: ANDI.

[27] Utami, S. (2011). Peranan Sistem Informasi Manajemen Untuk Pengambilan Keputusan Pengusaha Kecil. Jurnal Ekonomi dan Kewirausahaa, 11(2).

[28] Winkel, W. S. (2009). Bimbingan dan Konseling di Intitusi Pendidikan. Jakarta: Gramedia.

[29] Yakub. (2012). Pengantar Sistem Informasi. Yogyakarta: Graha Ilmu. 